\title{
Fractured identities: injury and the balletic body
}

DOI: $10.1177 / 1363459305048097$

\author{
Steven P. Wainwright, Clare Williams \& Bryan \\ S. Turner \\ King's College London, UK, Kings College London, UK \& \\ University of Cambridge, $U K$
}

ABSTRACT Social worlds shape human bodies and so it is inevitable that there are strong relationships between the body, professional dance and identity. In this article we draw on Bourdieu's notions of habitus, and various forms of capital, as the main theoretical framework for our discussion. Our ethnography of the balletic body elicited dancers and ex-dancers' perceptions of their bodies and sought to reveal some of the facets of their embodied habitus. The sheer physicality of their working lives - of feeling exhausted, sweaty and out of breath - is something dancers (like all athletes) become 'addicted to'. Ageing and injury can reveal this compulsion to dance and so dancers invariably find it very difficult to, for example, give up class once they retire from the stage; or miss a performance if they have a 'slight injury'. In other words, the vocational calling to dance is so overwhelming that their balletic body is their identity. In addition, there is an unremitting loop between individual habitus and institutional habitus (the ballet company), which affects both the meaning and management of injury. All our informants at the Royal Ballet (London: $n=20$ ) had suffered dance injuries. The injured, dancing body is perceived as an inevitable part of a career in ballet. Everyone spoke of the improved athleticism of dancers, and of the expansion in facilities to maintain healthy dancers. However, most dancers can expect several major injuries during their careers. Such epiphanies force dancers to confront their embodiment, and their thoughts invariably turn to their body, career and self. Critical injuries threaten to terminate a dancer's career and so endanger their embodied sense of self. On a more everyday level, dancing and performing with painful, niggling injuries is the norm.

\section{KEYWORDS body; dance and ethnography; identity; injury}

ADDRESS Steven P. Wainwright, Research Fellow, Florence Nightingale School of Nursing, King's College London, 57 Waterloo Road, London SE1 8WA, UK. [Tel: 020 78483214; fax: 020 78483219; e-mail: steven.wainwright@kcl.ac.uk] 
health: 9(1)

\section{Introduction}

Most of the current literature on dance injury focuses on the classification and the medical treatment of injury (Howse, 2000; Huwylet, 1999; Koutedakis and Sharp, 1999; Thomasen and Rist, 1996). In this article, in contrast, we draw upon our ethnographic research on the balletic body to outline an understanding of the experiences of embodiment of the injured dancer. In particular, we suggest that injury and ageing disrupt the practical accomplishments that underpin the balletic habitus and the dancer's identity. For, although ballet injury can terminate a dancing career, injuries are accepted as an inevitable part of the vocation of ballet. We utilize the Durkheimian insight that injury is mediated through the social bonding of dancers into a professional ballet company (Turner and Wainwright, 2003). This argument stems from Durkheim's (2001a) notion in Suicide, that social solidarity regulates the manifestation of individualism through - in Durkheim's phrase - the 'conscience collective', and that high suicide rates therefore express the absence of sufficient social capital. The social solidarity of the company is crucial in mediating between the damage to the individual body and the social manifestation of an injury as a medical condition in need of medical intervention.

We develop a framework for the study of classical ballet that situates the sociology of the body as a productive perspective on embodiment and dance. In particular, we adopt the approach of Pierre Bourdieu (Bourdieu, 1984; Bourdieu and Wacquant, 1992; Swartz, 1997) to understand the intimate connections between body, dance and identity. The point of this theoretical framework is to underpin our ethnographic data that explores the relationships between habitus (as a set of dispositions), physical capital (essentially, the material body), cultural capital (basically, the embodied knowledge of dance), injury and identity.

Research on the body has been chastised for privileging theorizing, ignoring the individual, and neglecting the practical experiences of embodiment (Turner, 1996; Watson, 2000). It is argued that little attention has been paid to the ways in which:

Specific social worlds invest, shape, and deploy human bodies.... One of the paradoxical features of recent social studies of the body is how rarely one encounters in them actual living bodies of flesh and blood. (Wacquant, 1995: 65)

Similarly, the growing academic dance literature mirrors a penchant for theorizing (Thomas, 1995). In contrast to our research, contemporary writings in the discipline of dance studies are dominated by disembodied postmodern readings of 'dance as texts' (Adshead-Lansdale, 1999; Fraleigh and Hanstein, 1999). Postmodern approaches to health suffer from a similar disembodied view of the social world in which, 'the brute materiality and obdurate reality of (diseased) bodies-with-organs are neglected or down played in favour of the body-without-organs or its Foucauldian fabricated 
equivalent' (Williams, 2001: 150). Ballet is a specific example of the more general point that, 'agents create and mould their bodies in accordance with the fields in which they are involved and the demands of those specific fields' (Crossley, 2001: 107).

This article, therefore, investigates the reciprocal relationship between the field of professional ballet and the shaping of the dancer's body. The seminal article by Wacquant (1995) - on the making of the boxer's body did, to some degree, act as a template for our study of dance. What is striking in Wacquant's (1995) article is the way that the objective structures of the social world of boxing are embodied in the boxer's habitus. For example:

The boxer wilfully perseveres in this potentially self-destructive trade because, in a very real sense, he is inhabited by the game that he inhabits ... a veteran middleweight who has rumbled on three continents for over a decade ... [commented], 'you can't (give it up) it's in your blood so much ... you can't give it up'. (Wacquant, 1995: 88, original italics)

Waquant (1995: 69) notes how thin, lanky boxers use reach, speed and technique to become 'boxers'; whereas shorter, stubby boxers use strength and toughness to become 'fighters' (or 'sluggers' or 'brawlers'). In other words, physical capital, in the form of body shape, tends to mould boxers into one of these styles or types of boxer. In Bourdieusian language the boxer's individual habitus is moulded by the institutional habitus of the boxing gym.

Within this article we draw on this Bourdieusian framework, of physical capital, cultural capital, individual habitus and institutional habitus, as a general theoretical context within which to situate the relationships between career, body, and identity. Injury constantly threatens to shatter the habitus of the classical dancer, which is sustained by a complex discipline of training, self-management, and ballet culture (Aalten, 1997; Brinson and Dick, 1996; Wulff, 1998). Ballet training produces a 'ballet habitus', both in the sense of a particular type of body, and also in the mastery of the dancing body. Furthermore, because the identity of the dancer is rooted in a ballet habitus from an early age, permanent injury is a profound crisis to the embodiment of the ballet dancer's identity. There can be few vocations in which professional capital (both physical and cultural) is so dependent on the athletic body and its presentation. Our study of ballet injury thus offers potentially rich insights into the production and destruction of an occupational habitus.

In this article we discuss two distinct but overlapping areas of dance injury. Firstly, we focus on the impact that injuries can have on individual identities, in terms of the physical, psychological, social and even spiritual effects of dance injury. Secondly, we explore some of the ways in which dance injuries are presented by, and negotiated between individuals and the institution of the ballet company. 


\section{Methods}

The lead author spent over 40 days in 2001 and 2002 conducting fieldwork at the Royal Ballet (London). This entailed 20 in-depth interviews with ballet staff (five of these were joint interviews with BST), and detailed observation of 'the company at work' in class, especially in rehearsal, and in performance. Focusing on injury and ageing, the interviews explored the perceptions of bodies and dancing careers of dancers $(n=9)$ and ex-dancers $(n=11)$ who are now coachers, administrators and character artists with the company. Seven of the dancers were not performing because of their current injuries; the other informants were not injured at the time of interview. All the participants signed a consent form that ensured anonymity and confidentiality. The interviews were tape-recorded and fully transcribed and analysed using grounded coding (Strauss, 1987). Pseudonyms are used in this report to ensure the anonymity of our informants.

\section{Fractured identities: some sequelae of dance injury}

Dance injuries result in physical, psychological, social, and even spiritual sequelae (Wainwright and Turner, in press). The intimate connection between self and career, commonplace in the social world of dance, is forcefully expressed by Sir Frederick Ashton, the founder Choreographer of the Royal Ballet, London (Kavanagh, 1996), when he speaks of his life as his work:

Choreography is my whole being, my whole life, my reason for living. I pour into it all my love, my frustrations, and sometimes autobiographical details. To me, in many ways, it has more reality than the life which I live, and I couldn't conceive of existing unless I could do choreography. (Vaughan, 1977: xvii)

From this perspective, it is clear that careers in ballet can be so entwined with an individual's identity that the consequences of injury are not just threats to a career in dance, but they are also threats to one's very identity as a person. Eric, a dancer in his mid-20s, illustrates this very clearly:

Eric: When you start getting a bit higher up the ladder, you start thinking about the roles that are really important for you and you do put a lot of things in your life on hold. ... It is a huge part of you and when you don't do it you do feel very strange. It's a real kind of empty, weird feeling. You don't know what to do with yourself and whole days just go by and you're just sat there like that [stares blankly into space]. It's the extremity of it all. One minute I was doing extraordinary things like jumping, landing, turning, and within a second you can't walk. It's literally in a split second, and that's very hard to come to terms with.

As Goffman (1972: 166) states: 'A body is a piece of consequential equipment, and its owner is always putting it on the line'. Ballet is a superb example of Goffman's claim because serious dance injuries, and retirement from dancing, are both major transitions that often have profound 
consequences for self-identity (Wainwright, 2001; Wainwright and Turner, 2003a; Wainwright and Turner, 2004). The quote from Eric graphically illustrates the effects of injury. If dancing fills your life, or even more so, if dancing is your life, then not dancing inevitably results in feeling lost and full of emptiness. This is similar for other athletes, and the sociology of sport provides some helpful insights into elite, high performance bodies and into the significance of injury and retirement within particular sporting subcultures (Laker, 2002; Leonard, 1993). For instance, several studies of professional sports have found that serious injury can have a major impact on the identity of elite athletes (Curry, 1993; Young and White, 1995; Young, White and McTeer, 1994).

On a more physical level, dancers described how the very act of 'being off' with an injury caused changes to their bodies, as it is only through a rigorous regime of daily dancing that dancers can maintain the extreme levels of fitness that are a defining trait of the balletic body. As Robert remarked:

Robert: But it's quite interesting when you stop dancing - because I gave up dancing two months ago - you do notice your body changes, even with doing Pilates [non weight-bearing body conditioning] and things. I've put on weight simply because I don't work the same way. That's one thing I've found with dance, you can never keep yourself as fit as you need to be to dance when you are not dancing. You can do all these exercises, you can go swimming, you can go running, but you are never actually quite as fit as you are when you actually dance.

For dancers then, dancing is an embodied necessity. Some dancers are just so used to working with their failing bodies that 'keeping going' becomes its own reward. Paradoxically, dancers also sometimes felt in peak physical condition and to be dancing at their very best just before their bodies gave out under the stress - as discussed by Vicky:

Vicky: I'm not 'off'. I'm just clinging on! I'm not quite 'off'. My neck and foot are both slightly dodgy. I'm doing OK really ... It's odd, because although I'm falling to bits at the moment, I feel quite strong. I've been doing so much work that I do actually feel strong. . . . Often it's the case that you'll have been dancing really well and feeling really good and I think perhaps you start to push yourself even more. There's the constant driving for something better.

Again, as might be expected, this bears a striking resemblance to studies of professional athletes which have found that injury and pain are normalized, and often hidden, in elite performers (Curry, 1993; Young and White, 1995; Young et al., 1994).

Ballet is a profession where your body is subject to daily intensive scrutiny by experts on the balletic body (Clarke and Crisp, 1984). Furthermore, the dancer's biggest critic will always be himself or herself. The social world of ballet is replete with examples of the Foucauldian notions of discipline, surveillance, and technologies of the self (Wainwright and Turner, 2003a), as the quotation by Dennis illustrates: 
Dennis: It's a very short career. It's very intense, and although it sounds very clichéd, you really are always auditioning. Every single day that you come to work, people are watching you. You're looking at yourself; your colleagues are looking at you, you're looking at colleagues. You're always being watched by somebody. So six weeks off, doing absolutely nothing - or no dancing - feels like an eternity. You're itching to get back, and if you can endure the hardship of getting back to full fitness, which obviously people do, it just tends to make you keener. You've just been so frustrated with not being able to do stuff, especially when you feel you're missing opportunities. Every rehearsal you miss you're missing a possible opportunity, never mind every week. ... It's a very tough career, very tough.

Dennis provides an articulate account of the differences that injury can make to a dancer's view of his/her body and career, and powerfully illustrates the significance of 'time off' through injury, which can be seen as a litany of daily losses of opportunities to further one's career. Most professional ballet dancers will retire by the age of 30 (Hamilton, 1998) and consequently, the accelerated timeline of a dancing career can accentuate the anguish of a slow and extended recovery from injury. Maria very poignantly described this painful process:

Maria: Your state of mind, it's in a very delicate state, a very delicate state, because you're talking about months. And for a ballerina nine months means a lot. In the long term, if you look at life altogether you say nine months - that's nothing. But for a ballerina it is; every single minute counts.... It is unbearable.

Although ballet dancing can be a difficult career on both a physical and a mental level, physical recovery from dance injury, as with illness in general, was invariably described as faster than the slow, and often troublesome, psychological recovery process (Corbin and Strauss, 1988; Sparkes, 1998; Williams, 2002). Recognizing this, many dance companies now employ psychologists to help dancers' psychological recovery in the wake of serious injury (Hamilton, 1998). The feelings of despair and devastation that are among the most serious consequences of a dance injury was a topic of conversation with Zelda:

Zelda: I haven't had a long long-term injury. I've had a month or so. It was devastating.... Psychologically, it was impossible to cope with.... At the beginning it's all a disaster, life is not worth it, you kind of want to jump out of the window. ... The worst thing is not that you are injured; it's the coming back through the rehabilitation ... psychologically it's horrendous because you have no confidence whatsoever, as you have something that's bothering you. The body is in a good state by now, but it doesn't feel like it used to and it takes forever to go back psychologically to where you were.

However, almost ironically, injury and the subsequent suffering could also be seen as important, possibly as crucial, in terms of the overall development of the artistic sensitivity of dancers, both men and women. So, for example, when Maria was asked how she felt her injury experiences might affect her ability as a dancer, she stated: 
Maria: Well, hopefully for the better. In my artistic side - definitely, because I look at things in a different way.... There are certain things, like I appreciate much more what it means to be an artist. How lucky we are that we can spread what we feel to the audience. And sometimes we get too confused and worried about the technical side that we forget that we are artists. I think that that is something that I haven't lost and that's something that my injury didn't diminish. You grow bigger, you know ... and to be an artist you have to achieve a certain level of technique and then to be able to forget about the technique and dance and enjoy it. You can't be a great artist without that base. ... And now you come to an age where you are more of a woman, a more mature person and you have spirit because you have suffered inside. You have been in a hospital, and been put in a plaster one time after another, and you look at it and you say, 'Am I ever going to put a pointe shoe on again?' And when you do get to the point where you put a pointe shoe on, the satisfaction. It makes you be happy. It makes you be enthusiastic about life. It makes you believe that you can do anything.

Errol's interview extract below also illustrates how injury appeared to be viewed almost as a 'test' of your vocation; where artistic capital was increased through suffering. The ability to dance again makes dancers appreciate something that can easily be taken for granted - the 'blessing' of one's 'calling' as a ballet dancer:

Errol: Mentally it was quite difficult. I was like, 'I can't dance again. Do I want to dance again? Do I ever want to do anything!'. I was off for about five months, but I have to say that I didn't really feel in top form for another four or five months.... When I came back I was somewhat re-energized. I found a new devotion and dedication.... You get a sense of how lucky you are to be doing something of this nature.

All of our interviewees accepted that ballet was becoming increasingly athletically demanding, but they also emphasized how they perceived ballet to be fundamentally different from other physically demanding sports. This universal belief was succinctly summed up by a leading ballet coach we interviewed, who stated: 'Ballet is an artist's job, not an athlete's job'. The importance of the emotional capital (Williams, 1998) to be accrued from the suffering of ballet dancers is emphasized by the following extract from Dame Antoinette Sibley, who was a famous ballerina and is now a member of the Ballet Board of the Royal Opera House:

One's got to believe in fairy tales up to a point, but I think it's better if you've really lived, seen the harsher side of life, if you've been hurt, if you've cried a little, if you've laughed a lot, if you've loved a lot. It makes a difference if you know everything, the lows and the heights, and love.... A lot of suffering can help you as an artist. Suffering can increase your sensitivity just as much as happiness can. (Newman, 1986: 105, 211)

This chimes with Stanislavsky's (1967: 53-5) idea that actors should draw on their 'emotional memory'. Similarly, a serious dance injury can be drawn upon in this way, in a transfiguration of a dancer's embodied artistry. 
Moreover, transformation through suffering, or the tragedy of torment and death is central to ballets such as Giselle (Wainwright and Williams, in press), Romeo \& Juliet, Manon, Mayerling, and Anastasia, all of which are important ballets in the Royal Ballet repertoire, and are regularly performed by the company (Bland, 1981; Brinson and Crisp, 1980; Craine and Mackrell, 2000; Edwards, 2003).

These insights on the role of suffering for ballet dancers indicate that although, in many ways, ballet dancing is similar to other sports, there are also profound differences. They also serve to illustrate how, while it is possible to read a ballet through its choreographic text, this method of study would be an odd and shallow method of understanding ballet, which is constituted by its performance. This reflects Becker's (1982) view that art is a process rather than a product. Ballet requires emotional performing bodies in order to come into existence. This observation means that the ballet aesthetic, like the aesthetic of any art that is a performance, cannot be properly understood in terms of textuality (Shusterman, 2000). Above all, dance demands that its aesthetic sensibility is a sensibility of movement. Hence the (disembodied) critical aesthetic of Adorno or Kant has been critiqued in a series of Bourdieusian analyses for their failure to grasp the aesthetic embodiment of the arts in general (Bourdieu, 1984), and of art forms such as ballet (Shusterman, 1992) and music (DeNora, 2000) in particular.

To conclude this section, it appears then, that for a variety of reasons, professional ballet is not just something that you do - in a very deep sense it is who you are. The great ballerina, Natalia Markarova, now retired, sums this up very eloquently:

Imagine it, for twenty five years I have been attempting the perfect pirouette from fourth position. ... I like to fight with my body, and achieve a victory over it. When you are working on some technical problem, even at the point when you despair of ever solving it, then it suddenly resolves itself. You feel so happy, so amazed because it now seems so simple. . . This is one of the dancer's greatest moments, even if, suddenly, it is lost again. This is art, and this is life: there is no difference. (Austin, 1978: 72, 89, our italics)

This is a particularly striking example, illustrating how the ballet dancer's habitus becomes conjoined with their embodied self-identity, of how being a dancer becomes the core of that person's embodied identity. The next section looks at the possible consequences of this, in relation to the form and presentation of injury within the institutional setting of the Company.

\section{The injured dancer within the institutional setting}

One of the consequences of this embodied identity is that it can be extraordinarily difficult, and sometimes impossible, for a dancer not to dance with an injured body. A recent interview with Tamara Rojo, principal 
dancer of the Royal Ballet, provides a powerfully dramatic example of this embodiment of identity and of the irresistible allure of performing (McCarthy, 2002: 16):

McCarthy: 'I was told that you danced. . . through a bursting appendix?

Rojo: I did ... I was dancing Clara in Nutcracker ... and I started shaking on stage. The pain was terrible... The company doctor sent me to a private hospital and they discovered that the appendix was burst and I was there for six weeks. But then I did something else stupid by dancing only two weeks later in the Spanish dance, and so I had to go back to hospital. It was completely wrong and I do not feel that anyone should do this. It really is not worth it.

Classical ballet is a career in which pain is a more or less permanent feature of the profession (Aalten, 1997; Brinson and Dick, 1996). In fact, one could argue that the permanence of pain in ballet is a measure of the validity of the charisma of a calling. Working with and through pain was something that everyone we spoke to viewed as normal, as the next excerpt illustrates:

Jessie: Individual dancers have very different pain thresholds. I mean, some dancers can go on with an injury that would have put another dancer off from day one, and others will go on and on and on. Sometimes to their own detriment because then it becomes absolutely chronic and it's worse in the long run. But no, some of them are fantastically able to just cope. They do. I mean, we sort of say, 'Dr Theatre' - you know, once you've got the make-up on, you get on there and you do dance things that in a studio perhaps you might not have been able to do. It is extraordinary, how the adrenaline, I think there's a chemical in there that actually deadens pain. It really, really does.... Sadly, a lot of exdancers do have terrible problems, hip problems or joint problems which cause them a lot of hardship. But probably because they worked on in their career with that chronic injury and then eventually they had to pay the price for it.

This theme of the remarkable pain relieving properties of 'Dr Theatre' is also exemplified in a quotation from Dennis, for whom 'the show just had to go on':

Dennis: At the moment I'm just recovering from a broken foot - it's my fifth metatarsal. I did it very unimpressively going down the stairs to the stage dressed up as the Mouse King (in Nutcracker) and I just went over on my ankle and broke - well it was a crush break. Unfortunately, because of the lack of time before I had to go on stage I couldn't find anyone in time, so I continued and did the dance. I did this dance number on a broken foot, which probably didn't help.

It has been argued that ballet dancers are happy to take painkillers on a routine basis to manage pain in order to perform (Bull, 1999; Kirkland and Lawrence, 1988). Percy, a 33-year-old dancer who was to retire at the end of the season, reiterated this view:

Percy: I don't think I've ever been on stage where there's not something now that hurts. .. I said to Jeremy Isaacs [then Director of the Royal Opera House, 
London], 'instead of free water can't you get Neurofen [Ibuprofen] to sponsor us', because if you shook every single dancer up, they would rattle with the amount of Neurofen inside their body!

The ability to dance through the pain is a leitmotiv of many ballet biographies (for example, Bull, 1999; Fonteyn, 1975; Kirkland and Lawrence, 1988, 1990; Newman, 1986; Solway, 1998). Moreover, success itself reinforces this physical and mental toughness and the sheer physicality of dancing is addictive. Leder (1990) has argued that the body is 'an absent presence' for, prior to disruption (injury, illness etc.) people typically perform their everyday social routines without mindfulness of their bodies as bodies. In contrast, dancers do have a remarkable ability to 'read their bodies', although these insights are sometimes obliterated by the allure of the stage:

Dennis: I guess one of the very relevant points that is interesting about dancers is that they have a tremendous ability to work with injuries ... whereas a $£ 100,000$-a-week footballer wouldn’t risk prolonging the injury. But with dancers, because of the nature of the short career, again it's going back to the same thing, they don't want to miss an opportunity. They don't want to miss a possible performance. And dancers will go on and on and on, often to their own detriment because they'll end with a serious injury when they could have actually treated it sooner. Rather than take the time off and miss something, dancers will actually endure a tremendous amount of pain and dance through it.

There is evidence that this distinction between sport and ballet is not quite as straightforward as Dennis believes. For example, an ethnographic study of the habitus of pain and injury in rugby union, and especially of the move from amateur to professional rugby, has shown how this shapes both the body and the meaning of injury (Howe, 2001). This is similar to the historical changes and the 'professionalization of ballet' that we have outlined in our study of the Royal Ballet (Wainwright and Turner, in press).

There appeared to be an unremitting loop between agency and structure, or in more Bourdieusian terms, between what we describe as individual habitus and institutional habitus. Pain is an example of the way that the individual agency of the dancer is reflected in the institutional structure of a dance company and vice versa in a continuous process of 'structuration' (Giddens, 1984), where the dancer's body is both the medium and the outcome of their innate physical capital. Chronic injuries could be partially produced and reproduced by the mutual dispositions of a 'culture of hardiness' by both individuals and the institution, as illustrated by Dexter, an ex-dancer who now coaches:

Dexter: Then I got a torn Achilles tendon, which they didn't really discover for 18 months. So for 18 months I was having cortisone injections until finally I couldn't stand it anymore. I finally couldn't stand the pain. I was dancing all the time but I couldn't, you know [go on]. It was agony to warm up, but the adrenaline would get me through the show.... One of the scariest things about the 
job [coaching] is having the responsibility of them [dancers] and knowing how much you can push, and how much you can't push, and of injuring someone in a rehearsal. You don't know whether they are genuinely tired, or whether they don't want to do it again. It's a fine line. My biggest responsibility is not injuring a dancer. That, touch wood, hasn't happened very often.... I think I did have a huge pain threshold too, and I know some people don't. I mean, you go like this to a boy [moves his hand slightly] and they roll around on the floor like one of those football players - [Names a famous dancer] a terrible wimp, terrible wimp!

Similarly, the mental toughness to work through the pain was seen as one feature that distinguished those who became professional dancers. Lisa, who now coaches leading dancers of the Royal Ballet, recalled her time teaching young dancers at the Royal Ballet School:

Lisa: Obviously some people were never going to make it in dance, because they didn't have the guts to come in every day and get on with it. They always had pain and it affected them; whereas some people had pain and it didn't affect them. So you could tell the people that were really going to make good company members.

This is a good example of habitus as what Ball (1998: 3) has described as, 'a processing of structure'. What we have called institutional habitus, a belief that 'the show must go on', becomes quite literally embodied in those dancers who are seen as the most likely to succeed in a professional ballet company. The pressure to perform is internalized by dancers, and becomes a fundamental part of their individual balletic habitus, as we saw in the quotes documenting the allure of the stage.

Dennis revealed another aspect of the inter-relationship between injury, individual and institutional habitus when he talked of performing or not performing as, effectively, a switch that is either on or off. In other words, you cannot just dance one of your favourite parts and not dance in other performances, as this goes against the 'unwritten code of conduct':

Dennis: Because everyone works very hard, and everyone has to do a lot of stuff that they don't particularly want to do and very few people - at the very, very top - get to pick and choose. They don't say, 'I'll do this because I like it, but I won't do this'. It's not allowed! It breaks the code of conduct almost. So, it's all or nothing. You're either on, or you're off, which is hard. Because if you do want to do a plum role then there might be many other things that you have to do alongside that and that might be the end of you, it might just push you over the edge and mean that you have to go off for a while. People do do it, they endure it and people push themselves through. I know that I have, and I can't think that there would be anyone who hasn't been on stage when they shouldn't have been.

In addition, the company itself needs its dancers on stage. At times 'the show' is under threat from a catalogue of injuries. Christina explained how she believed the pressures on dancers in the second, or understudy cast, increased the possibility of injury: 
Christina: We're always short of dancers. If one person goes off then there might be 20 changes in casting as everyone gets swapped around. You really want to do it and that's why you are here. ... What happens is the first cast gets rehearsed more. So if you are in the second cast, then you're not so prepared, and if someone in the first cast is injured you get thrown on. And there tends to be tension, and nervous energy, and extra rehearsals suddenly, and so your body is more likely to be injured.

The lengths to which ballet companies can go to in enabling dancers to keep performing despite injury is graphically illustrated by another quote from Dame Antoinette Sibley. Here she speaks of the effects of her own injury on her dancing, and of the way in which the choreographers Frederick Ashton (The Dream) and Kenneth MacMillan (Manon) created ballets for her 'good leg':

Well, the knee got progressively worse. For years I had to give up the fouettés [whipped turns] in Swan Lake because they were on the left leg. I never knelt in any way, shape or form in any ballet, on that leg ... I didn't jump off that leg, I had to change everything. And the right leg was wonderful, thank goodness. That's why Sleeping Beauty was not the problem of a Swan Lake: it's a right-leg ballet. And all the ballets I've created are right-leg ballets, The Dream, Manon. (Newman, 1986: 191)

We were also interested in perceived differences between ballet companies in their care of injured dancers:

Rudolf: Certainly I know that the Royal Ballet Company have always attempted to do the best to look after their dancer. That's their investment really ... there are one or two companies that don't perhaps look after the dancers as well as we do. Without wishing to name names, we've taken a young lady into the company ... she had a small injury in March, which should have meant, 'two weeks rest and you'll be fine'. However, the company concerned refused to let her take time off, insisted that she continued to perform a fairly rigorous schedule. She came to work with us in September, and she hasn't been on the stage [over four months later]. So we're paying for other people's lack of care.... Obviously the director of the company thought, 'Well, this girl's leaving; why should I bother?'. There are one or two companies who don't support dancers as well as us.

All the dancers and ex-dancers we interviewed had extremely positive views about the management and support of injured dancers within the company, which added to both their individual sense of attachment to the company, and to the overall social bonding of the company. Although numerous informants stated that the injury rate was 'very high' within the company, there was a view that the rehabilitation of dancers was now far faster. This was seen as partly due to Pilates body conditioning, which enables dancers to maintain very high levels of muscle tone (Bronhorst et al., 2001), but also to what were perceived as excellent, on-site, medical, physiotherapy and counselling services. Despite these advances, dancers 
are individuals and so their bodies may react in unpredictable ways to even the best treatments.

Finally in this section, we explore what can happen when injury results in the dancer having to cease performing permanently. Leaving the stage may involve a re-invention of the dancer's identity, a new way of presenting the self. Dudley reflected on how his body type and proneness to injury forced him to become a dance teacher:

Dudley: By the time I was 28 I decided that having been at it since I was ten, that I was burned out. I was having certain problems with my back and I went to see an orthopaedic surgeon and he said, 'If you don't stop you're going to have trouble'. So I stopped. . . . Those injuries caused me to re-think and I had to - and I use the word very strongly - I had to re-invent myself. I had to come back and re-invent myself.

Once Dudley gave up dancing on stage then he was no longer 'a dancer'. In a similar way injury can have a dramatic impact on the identity of sportsmen (Sparkes and Smith, 2003). Surely this phrase, 'I had to re-invent myself' exemplifies the embodiment of a dancer's identity. Even though Dudley remained within the balletic field, he perceived himself to be a profoundly different person. What is also extraordinary here is the way that Dudley describes his body as 'burned out' at the relatively tender age of 28. This meshes with the experience of the physicality of work for those working class youths who are, at the present time, fortunate to have a job. For example, Charlesworth (2000: 241), in his phenomenology of the working class body in Rotherham (South Yorkshire), seizes on this materiality in a quote from one of his informants: 'Ten mo'ore y'r ah labourin' and mi' body'll bi fucked, an' thi's s'many unemployed that thi can sack yer an' get someb'dy younger'. The body as physical capital is also a striking feature of the social world of boxing (Waquant, 1995). In ballet, however, it seems that the embodied cultural capital accrued during years of performance and rehearsal can offset the inexorable decline in physical capital experienced by ballet dancers, as we describe in more detail in papers on ageing and the balletic body (Wainwright and Turner, 2003a; Wainwright and Turner, 2004).

\section{Conclusion}

It seems that pain and injury are ever-present realities of ballet dancers' lives. Moreover, it is clear that injury destroys the embodiment of the classical ballet dancer. At the same time, the institutionalization of ballet has a direct impact on the form and presentation of injury. Ballet dancers in the modern company are kept fit, for example via Pilates body conditioning for 'new choreography', in order to avoid injury. At the same time, the dance repertoire is becoming ever more varied while new works are becoming ever more demanding (Wainwright and Turner, in press). In this 
sense, the ballet injury is socially constructed, because a ballet dancer may be expected to dance with a certain level of strain or injury. The spirit of the company is such that the ballet dancer is expected to manage pain. The discipline of their calling demands it.

Our entire sample had suffered dance injuries. The injured dancing body is perceived to be an inevitable part of a career in ballet. Everyone spoke of the improved athleticism of dancers, of the expansion in facilities to maintain healthy dancers, but also of the extreme physical challenges of contemporary choreography; and the perceived shortening of dance careers (Wainwright and Turner, in press). Similar factors are mirrored more generally in the global changes in training regimens and the increased fitness in the field of sport (Dyck, 2000; Dyck and Archetti, 2003). Within ballet, however, there is a growing aesthetic for almost skeletal hyperflexible (ephemeral) bodies that may be more prone to injury (Bronhorst et al., 2001; Wainwright and Turner, 2003a). All dancers can probably expect several major injuries during their careers. Such 'fateful moments' (Giddens, 1991) force dancers to confront their embodiment, and their thoughts invariably turn to their body, career and self. These severe injuries often require surgery, physiotherapy, a 'rehabilitation ballet teacher', and perhaps even counselling. Critical injuries threaten to terminate a dancer's career and so endanger his/her embodied sense of self. Thankfully, such overpoweringly fateful moments are relatively rare. On a more everyday level dancing, and performing, with niggling injuries is the norm. Injury is a sign of a dancer's vocation.

Dancer's attitudes to pain are embodied, and they epitomize the connections between the individual (dancer) and the (ballet) institution. Being a dancer requires a stoical attitude to pain - indeed, injury, pain and suffering were seen as playing a central role in the development of artistic sensitivity. Being a professional ballet dancer inevitably entails being injured with the unavoidable disruption of the everyday routines of class, rehearsal, and performance. For dancers, the vulnerability of the body (Wainwright and Turner, 2003b) has important implications for the 'tribulations of the self', for, 'in the reflexive project of the self, the narrative of self-identity is inherently fragile' (Giddens, 1991: 185). Our article is a contribution to the growing literature on 'the lived phenomenological body, with a view to understanding the multiple and diverse ways in which people experience their bodies, and how these experiences interact to shape identities and selves' (Sparkes and Smith, 2003: 301).

Bourdieu's corpus of work is widely viewed as a productive approach to both theory and research on the body (Shilling, 1993; Turner, 1992). In essence, Bourdieu links agency (practice) with structure (via capital and field) through the process of habitus. In plainer language, our social practices as agents are usually the result of various habitual schemas and dispositions (habitus), combined with various types of resources (capital) that we have accrued. These forms of capital are then activated by certain 
structured social conditions (field) that they both belong to, and reproduce and modify. In this article we have drawn on Bourdieu's concepts of habitus and capital (physical, cultural, and emotional) as a means to both illuminate our data and link our research with other Bourdieusian studies (Wainwright and Turner, 2003b) in, for example, the areas of health (Williams, 1998), boxing (Waquant, 1995) and working class experiences (Charlesworth, 2000).

In this article we argued that the ballet habitus is sustained by the sense of professional discipline and attachment to the ballet company. It is through the presence of collective emotions, or to use the language of Durkheim (2001b: 180), through the contagious emotional force of this 'collective effervescence', that injuries are sustained, as a sign of the vocation of the dancer. We have attempted to show how a comprehensive account of injury among ballet dancers would have to address the institutionalization of injury, for the social setting of injury constructs the conditions under which injury is possible. We provided examples of the ways in which the embodiment of ballet practices constitute the habitus of ballet. Major injury, such as a broken toe or a damaged knee, can often terminate the career of a professional dancer (indeed, one of the dancers we interviewed has now been forced to retire because of injury). Nevertheless, the majority of classical ballet dancers continue to perform with pain and injury. It is also clear that the vocational commitment of the ballet dancer, the effervescence of dancing and the spirit of the corps de ballet mean that an injured ballet dancer keeps dancing - often under the strict regime of a physiotherapist, a sports psychologist and a 'rehabilitation ballet teacher'. In other words, the affective community of the ballet company sustains the vocation of its dancers. In conclusion, an understanding of the meanings and management of pain and injury requires an ethnographic understanding of the embodiment of the individual injured dancer within their institutional setting.

\section{References}

Aalten, A. (1997). Performing the body, creating culture. In K. Davis (Ed.),

Embodied practices: Feminist perspectives on the body, pp. 41-59. London:

SAGE Publications.

Adshead-Lansdale, J., Ed. (1999). Dancing texts: Intertextuality in interpretation. London: Dance Books.

Austin, R. (1978). Natalia Makarova: Ballerina. London: Dance Books.

Ball, S. (1998). It's becoming a habitus: Identities, youth transitions and socioeconomic change. Paper presented at the British Educational Research Association Conference, Belfast.

Becker, H. (1982). Art worlds. Berkeley, CA: University of California Press. Bland, A. (1981). The royal ballet: The first fifty years. New York: Doubleday.

Bourdieu, P. (1984). Distinction: a social critique of the judgement of taste. London: Routledge. 
Bourdieu, P. and Wacquant, L. (1992). An invitation to reflexive sociology. Cambridge: Polity Press.

Brinson, P. and Crisp, C. (1980). A guide to the repertory: Ballet and dance. Newton Abbot: David \& Charles.

Brinson, P. and Dick, F. (1996). Fit to dance: The report of the national inquiry into dancers' health and injury. London: Calouste Gulbenkian Foundation.

Bronhorst, P. Rijven, M. Roes, A., Sirman, R., Staines, M. and Wuersten, S. (2001). Not just any body: Advancing health, well-being and excellence in dance and dancers. Ontario, Canada: Ginger Press.

Bull, D. (1999). Dancing away: A Covent Garden diary (Revised Edition). London: Methuen.

Charlesworth, S.J. (2000). A phenomenology of working class experience. Cambridge: Cambridge University Press.

Clarke, M. and Crisp, C. (1984). Dancer: Men in dance. London: British Broadcasting Corporation.

Corbin, J. and Strauss, A. (1988). Unending work and care; Managing chronic illness at home. San Francisco: Jossey-Bass.

Craine, D. and Mackrell, J. (2000). The Oxford dictionary of dance. Oxford: Oxford University Press.

Crossley, N. (2001). The social body: Habit, identity and desire. Thousand Oaks, CA: SAGE Publications.

Curry, T. (1993). A little pain never hurt anyone: Athletic career socialization and the normalization of sports injury. Symbolic Interaction, 16(3), 273-90.

DeNora, T. (2000). Music in everyday life. Cambridge: Cambridge University Press.

Durkheim, E. (2001a[1897]). Suicide. London: Routledge.

Durkheim, E. (2001b[1912]). The elementary forms of the religious life. Oxford: Oxford University Press.

Dyck, N. (2000). Games, sports and cultures. Oxford: Berg.

Dyck, N. and Archetti, P. (2003). Sport, dance and embodied identities. Oxford: Berg.

Edwards, L. (2003). In good company: Sixty years with the Royal Ballet. London: Dance Books.

Fonteyn, M. (1975). Autobiography. London: W.H. Allen.

Fraleigh, S.H. and Hanstein, P. (1999). Researching dance, evolving modes of inquiry. London: Dance Books.

Giddens, A. (1984). The constitution of society. Outline of the theory of structuration. Cambridge: Polity.

Giddens, A. (1991). Modernity and self-identity: Self and society in the late modern age. Cambridge: Polity Press.

Goffman, E. (1972). Interaction ritual. London: Allen Lane.

Hamilton, L.H. (1998). Advice for dancers: Emotional counsel and practical strategies. San Francisco: Jossey-Bass.

Howe, P.D. (2001). An ethnography of pain and injury in professional rugby union. International Review for the Sociology of Sport, 36(3), 289-303.

Howse, J. (2000). Dance technique and injury prevention (Third Edition). London: A\&C Black.

Huwylet, J.S. (1999). The dancer's body: A medical perspective on dance and dance training. McLean, VA: International Medical Publishing. 
Kavanagh, J. (1996). Secret muses: The life of Frederick Ashton. London: Faber \& Faber.

Kirkland, G. and Lawrence, G. (1988). Dancing on my grave: An autobiography. Harmondsworth: Penguin.

Kirkland, G. and Lawrence, G. (1990). The shape of love. London: Hamish Hamilton.

Koutedakis, Y. and Sharp, N.C.C. (1999). The fit and healthy dancer. Chichester: Wiley.

Laker, A. (2002). The sociology of sport and physical education. London: Routledge.

Leder, D. (1990). The absent body. Chicago, IL: University of Chicago Press.

Leonard, W.L. (1993). A sociological perspective of sport. New York: MacMillan.

McCarthy, D. (2002). Tamara Rojo: Interview. Dance Europe, 50, 12-17.

Newman, B. (1986). Antoinete Sibley: Reflections of a ballerina. London: Hutchinson.

Shilling, C. (1993). The body and social theory. London: SAGE Publications.

Shusterman, R. (1992). Pragmatist aesthetics: Living beauty, rethinking art. Oxford: Basil Blackwell.

Shusterman, R. (2000). Performing live: Aesthetic alternatives for the ends of art.

New York: Cornell University Press.

Solway, D. (1998). Nureyev: His life. London: Weidefield \& Nicholson.

Sparkes, A.C. (1998). Athletic identity: An Achilles' heel to the survival of self. Qualitative Health Research, 8(5), 644-64.

Sparkes, A.C. and Smith, B. (2003). Men, sport, spinal cord injury and narrative time. Qualitative Research, 3(3), 295-320.

Stanislavsky, K. (1967). On the art of the stage. London: Faber \& Faber.

Strauss, A.L. (1987). Qualitative Analysis for Social Scientists. Cambridge: Cambridge University Press.

Swartz, D. (1997). Culture and power: The sociology of Pierre Bourdieu. Chicago, IL: University of Chicago Press.

Thomas, H. (1995). Dance, modernity and culture: Explorations into sociology of dance. London: Routledge.

Thomasen, E. and Rist, R.A. (1996). Anatomy and kineseology for ballet teachers. London: Dance Books.

Turner, B.S. (1992). Regulating bodies: Essays in medical sociology. London: Routledge.

Turner, B.S. (1996). The body and society. London: SAGE Publications.

Turner, B.S. and Wainwright, S.P. (2003). Corps de Ballet: The case of the injured ballet dancer. Sociology of Health \& Illness, 25(4), 269-88.

Vaughan, D. (1977). Frederick Ashton and his ballets. New York: Knopf.

Wacquant, L.J.D. (1995). Pugs at work: Bodily capital and bodily labour among professional boxers. Body \& Society, 1(1), 65-93.

Wainwright, S.P. (2001). Royal Mistress: Monica Mason remembers, an interview with Steven P. Wainwright. Dance Now, 10(4), 48-60.

Wainwright, S.P. and Turner, B.S. (2003a). Ageing and the dancing body. In C. Faircloth (Ed.), Ageing bodies: Meanings and perspective, pp. 259-92. Boston, MA: Alta Mira Press.

Wainwright, S.P. and Turner, B.S. (2003b). Reflections on embodiment and vulnerability. Journal of Medical Ethics: Medical Humanities, 29, 4-7. 
Wainwright, S.P. and Turner, B.S. (2004). Narratives of embodiment: Body, ageing, retirement and career in Royal Ballet dancers. In H. Thomas and J. Ahmed (Eds.) Cultural Bodies: Ethnography and Theory, pp. 98-120. Malden, MA: Blackwell.

Wainwright, S.P. and Turner, B.S. (in press). Epiphanies of embodiment: Injury, identity and the balletic body. Qualitative Research, 4(3).

Wainwright, S.P. and Williams, C. (in press). Giselle, madness and death. Journal of Medical Ethics: Medical Humanities.

Watson, J. (2000) Male Bodies: Health, culture and identity. Buckingham: Oxford University Press.

Williams, C. (2002). Mothers, young people and chronic illness. Aldershot: Aldgate.

Williams, S.J. (1998). 'Capitalising' on emotions? Rethinking the inequalities in health debate. Sociology, 32(1), 121-39.

Williams, S.J. (2001). Sociological imperialism and the profession of medicine revisited: where are we now? Sociology of Health and Illness, 23(2), 135-58.

Wulff, H. (1998). Ballet across borders: Career and culture in the world of dancers. Oxford: Berg.

Young, K., White, P. and McTeer, W. (1994). Body talk: Male athletes reflect on sport, injury, and pain. Sociology of Sport Journal, 11(2), 175-90.

Young, K. and White, P. (1995). Sport, physical danger and injury: The experiences of elite woman athletes. Sociology of Sport \& Social Issues, 19(1), 45-61.

\section{Author biographies}

STEVEN P. WAINWRIGHT'S research focuses on three areas: the Sociology of Health and Illness (especially innovative health technologies); Medical Humanities (especially narratives of ageing and death in painting, opera and ballet); and the Sociology of the Body (especially the reciprocal relationships between the arts, the social sciences and medicine - and the theme of the embodiment of vulnerability).

CLARE WILLIAMS' research focuses on four areas within Sociology of Health and Illness: innovative health technologies, particularly those related to genetics; sociology of ethics; gender, health and illness; practitioner education.

BRYAN S. TURNER'S research focuses on four areas: Medical Sociology (particularly the body and society); Political Sociology (especially citizenship and human rights); the Sociology of Religion (chiefly Islam); and Social Theory (especially Classical Social Theory). He sees these four domains as related via the theme of the body and embodiment. 